\title{
The journey from moral inferiority to post-traumatic stress disorder
}

\author{
What has been learned over the past century about the psychological injuries of war?
}

O ne of the striking differences between recent conflicts and the conflagrations of the past century is that the number of physical casualties has been drastically reduced, a change that has placed greater focus on the psychological costs of war. To place the enormity of earlier losses into context: around $14 \%$ of those who served in World War I died (over 60000 Australians), and a further $40 \%$ (more than 156000 men and women) were wounded, gassed or taken prisoner - at a time when the nation's population was only 4.9 million. ${ }^{1}$

\section{"the rates of psychiatric disorder in veterans following [combat and peacekeeping deployments] are ... quite similar"}

Those who survived the Great War were regarded as fortunate, even if they returned home with crippling injuries. There was often little empathy for the psychological wounds of the veterans, construed by many as reflecting moral inferiority, compensation-seeking or "poor seed". In particular, there was considerable debate within the medical profession as to whether the traumatic neurosis of war - shell shock - was organic or psychogenic in origin. $^{2}$

\section{Recognition of post-traumatic stress disorder}

Veterans of the Vietnam War confronted the medical establishment in the United States and Australia about the lack of understanding for their mental suffering shown by veterans' affairs officials. They demanded that quality scientific research be undertaken to better characterise the nature and cause of their psychological injuries, as well as to facilitate the development of effective treatments. Independent research, including the seminal US National Vietnam Veterans' Readjustment Study (NVVRS), showed that post-traumatic stress disorder (PTSD) was not explained by a desire for compensation, but was caused by the cumulative burden of exposure to the horrors and privations of combat. ${ }^{3-5}$ The NVVRS found that the lifetime prevalence of PTSD in Vietnam War veterans was $18.7 \%{ }^{3}$

It is ironic that "traumatic neurosis" (an earlier name for PTSD) had been well characterised as early as $1890,{ }^{6}$ but social and political factors had subsequently prevented its being systematically investigated. Over the past three decades, much has been learned by a generation of high-quality research that has used epidemiological tools to assess the aftermath of both combat and peacekeeping missions. ${ }^{5}$ The mental health sequelae of major deployments since 1990 have been systematically studied, and the mental health of the entire Australian Defence Force (ADF) was documented in 2010.7 The findings of these investigations highlight that exposure to human suffering, the risk of death and active involvement in combat are not only the major risk factors for PTSD, but also for major depressive disorder and other anxiety disorders. ${ }^{4,5,7}$ Furthermore, the similarities of traumatic exposures during modern peacekeeping operations are often greater than the differences experienced during deployment in a declared combat zone; the rates of psychiatric disorder in veterans following the two types of deployment are therefore quite similar. ${ }^{7}$

Suicidal ideation and suicide are of particular concern in veterans with PTSD, and the number of active duty suicides in the US armed forces over the past decade has caused increasing concern. ${ }^{8}$

While investigators routinely find substantial levels of psychiatric disorder in former members of the armed forces, the rates in currently serving personnel often do not differ substantially from those for the general community; nor are the rates of psychiatric disorder in deployed and non-deployed military personnel strikingly different, despite traumatic combat experiences. It should be remembered, however, that those who enlist in the defence forces are generally fitter than the population from which they are recruited, and this healthy worker effect is amplified by selecting the more resilient for deployment. ${ }^{7-9}$

\section{Prevention and support}

Selection processes - no matter how rigorous - cannot entirely avert the psychological injuries caused by repeated exposure to traumatic events. Lifetime exposure to traumatic stress (including pre-enlistment events) needs to be taken into account when calculating the risk of PTSD. Deployment rotation cycles that limit the periods of exposure are equally critical for managing risk.

A recent review by the US Institute of Medicine of military programs that aim to reduce the risk of PTSD highlighted the fact that there is little systematic evidence for the effectiveness of the most widely used approaches, such as psychoeducation, emotional decompression, psychological debriefing and resilience training, so that more research is needed. ${ }^{10}$ Postdeployment screening was the only approach endorsed by the review, and has been used by the ADF since 1998. Early recognition of PTSD not only enables rapid diagnosis and intervention, but also assists when dealing with other barriers to effective care, such as stigmatisation of the patient. ${ }^{11}$ Adequate training 
of medical and mental health staff in understanding the various manifestations of traumatic reactions (not just PTSD) is critical. Medical providers are often unaware of the military service of discharged veterans, so it is also essential that this information is routinely requested. High-risk groups, such as the physically ill and injured, require regular screening and follow-up, as delayed-onset PTSD is now recognised to be much more prevalent than was previously thought, particularly in veterans. ${ }^{11}$

\section{More research into treatment is needed}

The compelling need for better treatment outcomes has led to substantial investment in research programs by departments of defence and veterans' affairs in the US, the Netherlands, the United Kingdom and Australia. ${ }^{12}$ Recent developments include the identification of epigenetic markers for PTSD, and recognition of the role of inflammation in its aetiology. ${ }^{13}$ Mild traumatic brain injury as a risk factor is also being extensively studied in military populations, highlighting the importance of the integrity of neural networks. ${ }^{14}$

Some effective treatments for PTSD have been comprehensively investigated, including cognitive behaviour therapy, eye movement desensitisation and reprocessing therapy, and antidepressant medication therapies, and it has been found that the effect size of these treatments is often smaller in veterans than in patients with PTSD following single-incident traumas. ${ }^{11}$ The prolonged hypervigilance and repeated exposure to traumatic experiences that characterise military deployments cause more significant neurobiological disturbances (eg, reduced anterior cingulate cortex volume), and conditioned traumatic triggers are less amenable to extinction. ${ }^{15}$ This profound neurobiological dysregulation needs to be targeted by treatment, with potential roles for both pharmacological and psychological interventions. ${ }^{15}$

The battle during World War I between organic and psychogenic models of post-traumatic stress was misguided. PTSD is a multifaceted disorder, in which biological, psychological and social components are entwined in its aetiology, and must therefore be considered in any recovery strategy. An effective way to honour the suffering of those who fought in World War I is to ensure that our care for the current generation of veterans is diligent and informed by independent and adequately funded high-quality science.

Competing interests: We receive funding from the Department of Veterans' Affairs and Department of Defence, and are advisors on mental health to these departments. Alexander McFarlane is a Group Captain in the Royal Australian Air Force Specialist Reserve.

Provenance: Commissioned; externally peer reviewed.

References are available online at www.mja.com.au. 
1 Australian War Memorial. First World War 1914-18 [website]. https://www.awm.gov.au/atwar/wwl (accessed Mar 2015).

2 Butler AG, editor. The official history of the Australian Army Medical Services in the War of 1914-1918. Vol. 3: Special problems and services. Canberra: Australian War Memorial, 1943.

3 Dohrenwend BP, Turner JB, Turse NA, et al. The psychological risks of Vietnam for U.S. veterans: a revisit with new data and methods. Science 2006; 313: 979-982.

4 Wells TS, Miller SC, Adler AB, et al. Mental health impact of the Iraq and Afghanistan conflicts: a review of US research, service provision, and programmatic responses. Int Rev Psychiatry 2011; 23: 144-152.

5 Sundin J, Herrell RK, Hoge CW, et al. Mental health outcomes in US and UK military personnel returning from Iraq. $\mathrm{Br} J$ Psychiatry 2014; 204: 200-207.

6 Seguin EC. Traumatic neuroses. In: Sajous CE, editor. Annual of the universal medical sciences: a yearly report of the progress of the general sanitary sciences throughout the world. Vol. III. Philadelphia: FA Davis, 1890: N1-N8.

7 McFarlane AC, Hodson SE, Van Hooff M, Davies C. Mental health in the Australian Defence Force. 2010 ADF Mental Health and Wellbeing Study: full report. Canberra: Department of Defence, 2011.

8 Kang HK, Bullman TA, Smolenski DJ, et al. Suicide risk among 1.3 million veterans who were on active duty during the Iraq and Afghanistan wars. Ann Epidemiol 2015; 25: 96-100.
9 Larson GE, Highfill-McRoy RM, Booth-Kewley S. Psychiatric diagnoses in historic and contemporary military cohorts: combat deployment and the healthy warrior effect. Am J Epidemiol 2008; 167: 1269-1276.

10 Denning LA, Meisnere M, Warner KE, editors. Preventing psychological disorders in service members and their families: an assessment of programs. Washington, DC: National Academies Press, 2014.

1 Australian Centre for Posttraumatic Mental Health. Australian guidelines for the treatment of acute stress disorder and posttraumatic stress disorder. Melbourne: Australian Centre for Posttraumatic Mental Health, 2013.

12 US Departments of Defense, Veterans Affairs, Health and Human Services, and Education. National research action plan. Responding to the executive order "Improving access to mental health services for veterans, service members, and military families (August 31, 2012)". Washington, DC: US Departments of Defense, Veterans Affairs, Health and Human Services, and Education, 2013.

13 Uddin M, Aiello AE, Wildman DE, et al. Epigenetic and immune function profiles associated with posttraumatic stress disorder. Proc Natl Acad Sci USA 2010; 107: 9470-9475.

14 Rosenfeld JV, McFarlane AC, Bragge P, et al. Blast-related traumatic brain injury. Lancet Neurol 2013; 12: 882-893.

15 Pitman RK, Rasmusson AM, Koenen KC, et al. Biological studies of post-traumatic stress disorder. Nat Rev Neurosci 2012; 13: 769-787. 